\title{
A NEW SPECIES OF OPHIUROIDEA FROM THE COAST OF KII PENINSURA, JAPAN
}

$\operatorname{AUTHOR}(\mathrm{S})$ :

Irimura, Seiichi

\section{CITATION:}

Irimura, Seiichi. A NEW SPECIES OF OPHIUROIDEA FROM THE COAST OF KII PENINSURA, JAPAN. PUBLICATIONS OF THE SETO MARINE BIOLOGICAL LABORATORY 1968, 15(5): 353 356

ISSUE DATE:

1968-03-25

URL:

http://hdl.handle.net/2433/175484

RIGHT: 


\title{
A NEW SPECIES OF OPHIUROIDEA FROM THE COAST OF KII PENINSURA, JAPAN ${ }^{13}$
}

\author{
SEIICHI IRIMURA \\ Totsuka Senior High School, Yokohama
}

With 1 Text-figure

No species belonging to the genus Ophiolepis of Ophiuroidea has hitherto been recorded from the coast of Japan, but only two species, $O$. cincta and $O$. annulosa, from the Okinawa Islands.

Recently I received a littoral ophiurid specimen from Prof. H. UтімомI, Seto Marine Biological Laboratory of Kyoto University. The specimen was collected in the vicinity of Seto by one of the students visited the laboratory for the marine biological course in August, 1967 and handed to Prof. Uтіnomi for identification.

As a result of the study, the specimen is considered to be a new species of the genus Ophiolepis.

Before going further, I wish to express my sincere gratitude to Prof. H. UTINOMI for his kindness in offering this valuable specimen to me for examination, and to Dr. T. TokrokA, Seto Marine Biological Laboratory of Kyoto University, for his kind advices in preparation of the manuscript.

Ophiolepis utinomii, sp. nov.

Holotype: SMBL-Type 205, deposited in the museum of the Seto Marine Biological Laboratory.

Type locality: Hatakejima Island, at the head of Tanabe Bay, Wakayama-ken; littoral zone.

Measurement of holotype: Disk diameter $10 \mathrm{~mm}$, arm length $17 \mathrm{~mm}$.

Description: Disk circular in outline, hemispherical in shape, higher than arms, and covered by scales in two sizes; larger scales include a rounded convex central plate and many fan-shaped convex scales which decrease in size towards the interbrachial marginal disk, and are each surrounded by a single regular row of squarish small scales. Sets respectively formed of a larger scale and surrounding small scales are imbricated one another. The disk margin is encircled by a row of large spherical tubercles, three or four on an interbrachial margin and two on a brachial margin;

1) Contributions from the Seto Marine Biological Laboratory, No. 479.

Publ. Seto Mar. Biol. Lab., XV (5), 353-356, $1968 . \quad$ (Article 22) 

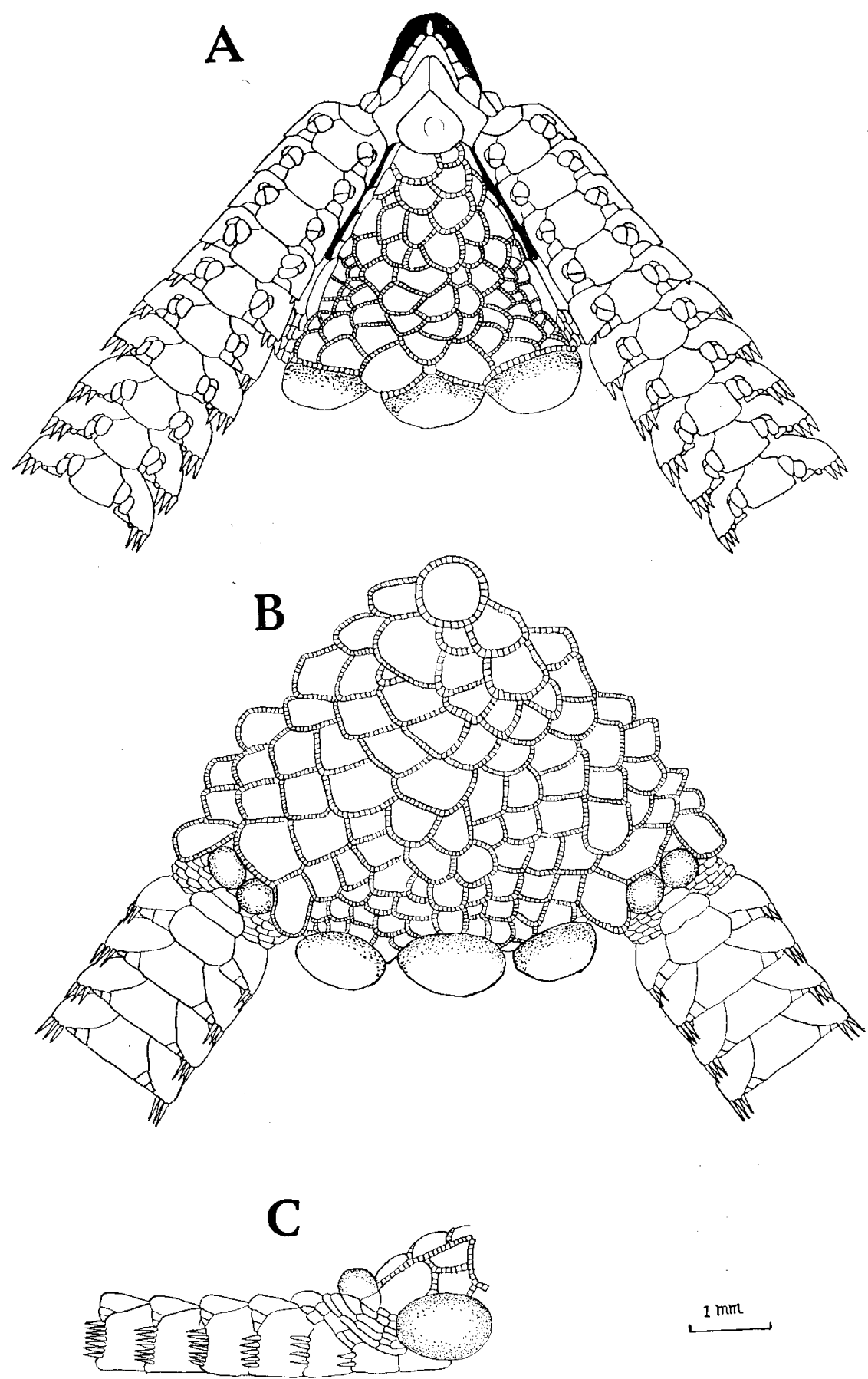

Fig. 1. Ophiolepis utinomii n. sp. A. Disk, oral view. B. Disk, aboral view. C. Basal arm and extra plates, lateral view. 
those on the interbrachial margin are larger than brachial ones. Radial shields moderate, twice as long as broad, separated from each other by a large scale and surrounding small squarish scales. The extra plates are extending from the distal genital plate to the radial shield and the third dorsal arm plate; they are minute and abundant.

On the ventral side of the interbrachial space, larger scales are flat and as small as those along the dorsal margin. Genital slits extend from the lateral edge of the oral shield to the half way point towards the disk margin. Genital plates slender, the distal one the longest. The oral shield roughly triangular with rounded basal corners and as long as wide; the proximal angle sharp, the distal margin rounded. Adoral shields are long, widened distally, and broadly contact with each other. Oral plates narrow and triangular. On the apex of the jaws, there is an unpaired conical papilla. Oral papillae five in number; proximal three squarish and smaller than the rest, and especially the penultimate one is the largest of all.

Arms short and stout, tapering gradually. The first to third dorsal arm plates small and embraced laterally by groups of extra plates. The following ones in basal pentagonal, broader than long, and with the distal margin wider than the proximal; respectively keeping a broad contact with the preceding and the following plates. Supplementary plates are divided into two or sometimes three pieces, extending downwards in an acute angle. Further distally, dorsal arm plates become triangular in shape, as long as wide, and separated from adjoining ones by lateral arm plates; supplementary plates reduced to minute papillae on the margins of the dorsal arm plate.

Ventral arm plates rectangular in the basal part, as long as wide, and with the distal margin slightly longer than the proximal, a broad contact being kept between adjoining plates. Ventral supplementary plates single and squarish in basal, but in the following arm joints they are divided into two pieces and extend downwards in an acute angle. Further distally, the shape of ventral arm plates changed to pentagon, supplementary plates reduced to minute papillae attached to the lateral arm plate.

Lateral arm plates very broad. Arm spines slender, acute, and half as long as arm joint; seven in number basally, but gradually falling to three distally. Tentacle papillae three on each pore, of which two scales are flat and of the same size, while the third one is reduced.

Colour of the specimen in alcohol: The dorsal disk and arms grayish brown, the ventral side and arm spines white.

Remarks: The present species belongs evidently to the genus Ophiolepis, but clearly differs from any of known species in having a row of large spherical tubercles encircling the disk and in the detailed appearance of the ventral supplementary plates.

The related species, $O$. cincta Müller \& Troschel, also has the hemispherical disk that is ornamented with sets of larger and smaller scales imbricated one another. 
However, $O$. cincta is easily distinguished from $O$. utinomii sp. nov. in having on each arm joint a row of armatures consisting of supplementary dorsal arm plates, three or four arm spines, and two tentacle scales, but no supplementary ventral arm plates.

Also the present new species is closely related to $O$. crassa Nielsen which has three tentacle scales and two supplementary dorsal and the same number of supplementary ventral arm plates, but the latter differs from the former in having the flat disk, larger radial shields, one to three rows of small irregular scales on the disk, and three to four arm spines.

\section{LITERATURE CITED}

Matsumoto, H. 1917. A monograph of Japanese Ophiuroidea, arranged according to a new classification. Journ. Coll. Sci., Imp. Univ. Tokyo, XXXVIII, 2.

Müller, J. und F. H. Troschel 1842. System der Asteriden.

Murakam, S. 1943. Report on the Ophiurans of Yaéyama, Ryukyu. J. Dept. Agr., Kyusyu Imp. Univ., VII, 5.

Nielsen, E. 1932. Paper from Dr. Mortensen's Pacific Expedition 1914-16. LIX. Ophiurans from the Gulf of Panama, California, and the Strait of Georgia. Vidensk. Medd. fra Dansk naturh. Foren., 91. 